\title{
Breeding Places and Migrations of the Eel.
}

\author{
By Dr. Johs. Sснмidt, Copenhagen.
}

I $\mathrm{N}$ an article in Nature ten years ago (August 22, 1 I912, p. 633) I gave a review of the position at that time of the question of the breeding grounds of the freshwater eel (Anguilla vulgaris). We had then been working for seven or eight years upon the question, and it was our intention to pursue the work further by means of investigations extending across the Atlantic.

In the ten years then following falls the period of the Great War. This rendered work at sea impossible. We research, partly from various trading ships plying on transatlantic routes, and partly from two schooners kindly placed at our disposal by the owners ( $\mathrm{I}^{2} \mathrm{I}^{-}-$ 1914, the Margrethe, 90 tons; 1920-21, the Dana, $55^{\circ}$ tons).

I shall in the following give a brief survey of the discoveries made regarding the breeding places of the eel since my article in NATURE in I9r2, adding also some remarks on the immigration of the eel-fry to

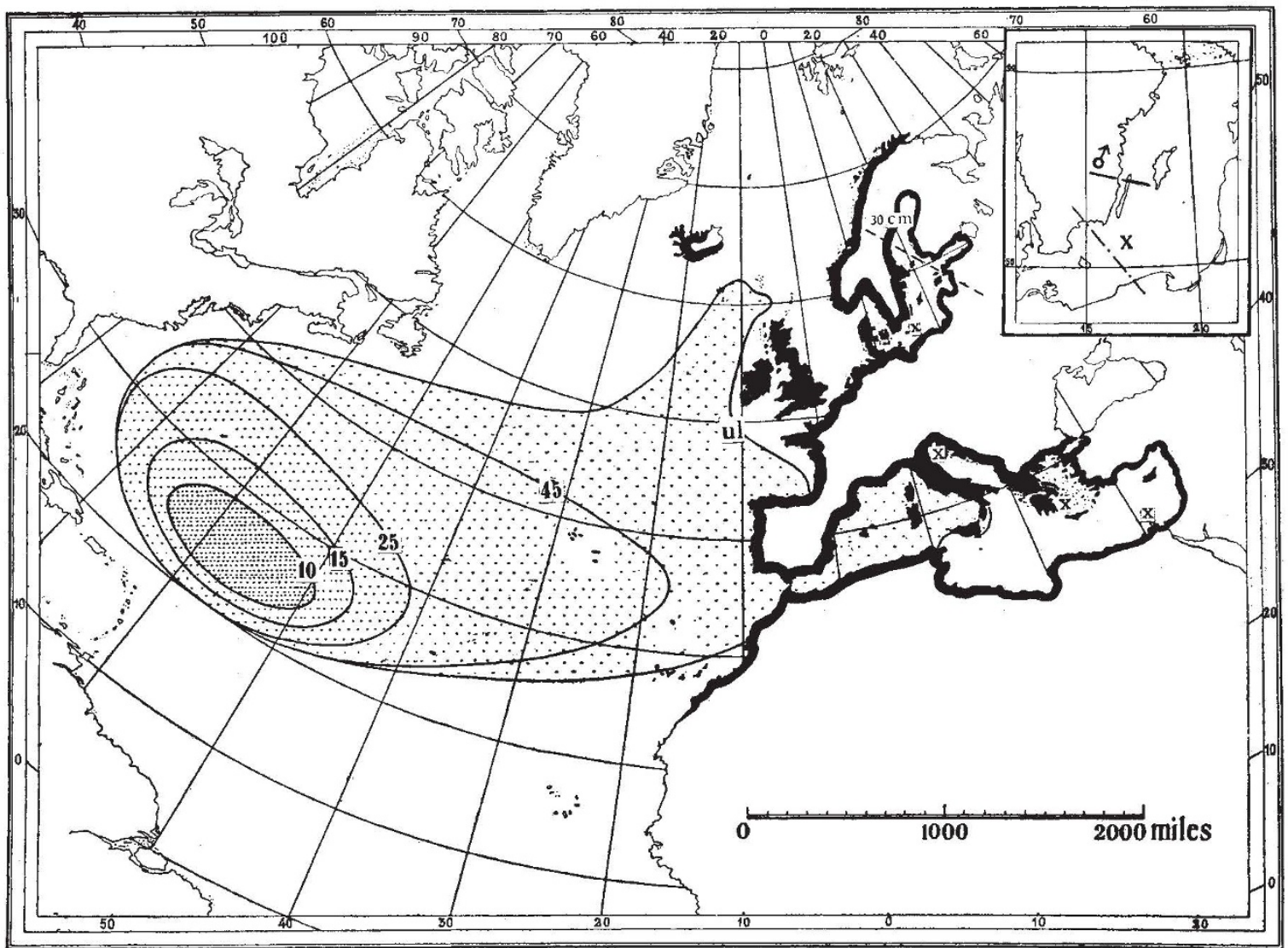

F1G. 1.--European eel (Anguilla vulgaris). Spawning places (bounded by innermost-10 mn.-curve); distribution of larva (dotted area) and of adults (black strip along the coasts where the eel occurs).

The curves show limits of occurrence; i.e. larva less than $25 \mathrm{~mm}$. have only been found inside the $25 \mathrm{~mm}$. curve, etc. The outermost curve denotes the limit of occurrence of unmetamorphosed larva $(u l), \delta$ and $30 \mathrm{~cm}$. (in the Baltic) of male eels and of eels less than $30 \mathrm{~cm}$. in length. $\mathrm{X}$ : easternmost records of unpigmented elvers (Baltic and Mediterranean).

managed, however, partly before and partly after the war, to carry out an investigation covering the greater part of the northern temperate waters of the Atlantic, and the question, Where does the eel breed? can now, in the main, be considered solved. At the same time, we have ascertained the duration and extent of the migrations of the eel-fry.

The previous investigations had been undertaken with the well-equipped research vessel Thor, but its radius of action would not suffice for transatlantic cruises. From rgI3 until r92I, when the Danish Government acquired the mine-sweeper Dana to replace the Thor, we were obliged to make our investigations from ships without any special equipment for marine
Europe. For further details I must refer any readers interested to my recently published paper in the Philosophical Transactions. ${ }^{1}$

In my article in Nature (August 22, I9I2, p. 633) I summed up the position as follows: "We cannot say as yet where exactly the spawning takes place, and but little more than that the spawning places must lie in the Atlantic beyond the Continental Slope, and that they must be in the Northern Atlantic."

The smallest (youngest) developmental stage of the eel then known to us was a larva of $34 \mathrm{~mm}$. length. In order to say anything definite as to where in the

1 Philosophical Transactions of the Royal Society of London, Series B. No. 385 , vol. 211 , pp. 179-208, 1922 . 
Atlantic our eels did breed, we had to find far younger stages, for a larva so large as $34 \mathrm{~mm}$. might well be imagined to have moved a great distance from the spot where it came into the world. Nor was it enough to find a few isolated specimens of the youngest stages; a spot which could be declared to be the site where the

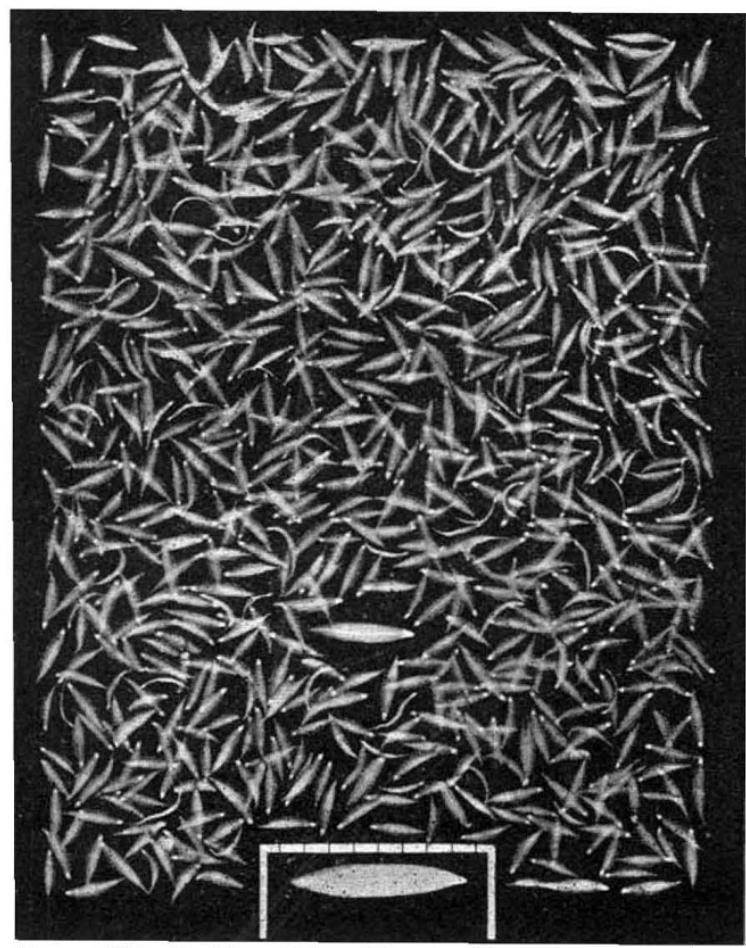

FIG. 2.-Sizes of eel larvæ (Ang, illa inulgaris) caught in a single haul of two hours' duration at Dana Station 871 (lat. $27^{\circ}$ i $5^{\prime} \mathrm{N}$., long. $6 \mathrm{r}^{\circ} 35^{\prime}$ W.) in the western Atlantic, June 27, xg20, depth about 50 metres. About 800 specimens of $\mathrm{O}$-group and $\mathrm{x}$ of $\mathrm{I}$-group are shown. A II-group specimen, length $74 \mathrm{~mm}$., from the eastern Atlantic, is shown for comparison. Reduced to about one-quarter (see the centimetre-scale).

great hosts of eels from the European continent assemble for their spawning must necessarily yield earliest stages of the offspring in great numbers.

The task before us, then, was to chart the distribution of the various developmental stages of eel-larvæ, from the oldest, about $7 \frac{1}{2} \mathrm{~cm}$. long-which we knew from previous investigations were to be found off the coasts of Western Europe and in the Mediterranean-to the earliest tiny stages which no one as yet had ever seen. If we could ascertain where, and at what seasons, these tiny larvæ were found, then we should at the same time have discovered where and when the eels spawn. Once it was known where the various sizes (age-groups) of growing larvæ occurred, it would be possible to form an idea as to the extent and duration of the migrations of the eel-fry from the breeding grounds to the fresh waters of Europe.

These years of research have been rich in excitement and suspense; disappointment alternating with encouraging discoveries, and periods of rapid progress with others during which the solution of the problem seemed wrapped in deeper darkness than ever. One is tempted to describe the investigations in their chronological sequence, from first to last, in order to show how by slow degrees, advancing step by step, we came to see great parts of the life-history of the eel emerge from the darkness that surrounded it. The question of space, however, precludes this. We must content ourselves with setting forth the facts as they now appear, after eighteen years of work, and seeing what conclusions may be drawn from them.

The chart Fig. I gives us the main sum of these many years' investigations into the distribution of the eel larvæ. This may be briefly stated as follows: The larvæ of our European eel (Anguilla vulgaris) are found distributed across the whole of the Atlantic Ocean from off the coasts of Europe to those of the United States. They increase in number, but decrease in size, as we pass from the European side towards America. The curves on the chart show that the spawning grounds comprise a restricted area in the western Atlantic, north-east and north of the West Indies, between $65^{\circ}$ and $48^{\circ}$ long., for here-and here only-are the youngest, newly hatched larvæ found. The eel spawns at the close of the winter and during spring. In April the larvæ had an average length of $12-13 \mathrm{~mm}$., in June 25 , and in October $35-40 \mathrm{~mm}$. During their first summer the larvæ are found only in the western Atlantic. Enormous quantities of these first-year larvæ (the O-group, as we call them) are found at this season west of $50^{\circ} \mathrm{W}$. long. In June 1920, when we were working there with the schooner Dana, it was impossible to draw a net through the upper water layers without bringing them up in quantities, and we often took several hundred specimens at one haul, as shown in the illustration Fig. 2.

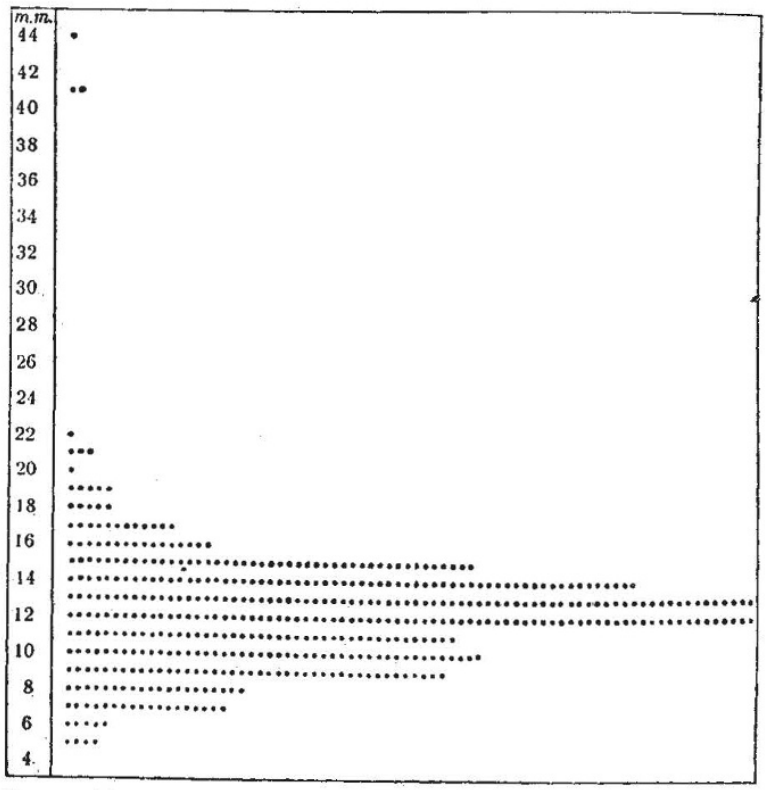

FIG; 3.-European eel (Anguilla vulgaris); western Atlantic (west of $50^{\circ}$ long. W.), Dana Stations $935^{\circ} 94^{8}$, April 1921; C-group and 3 specimens of I-group.

We are therefore excellently acquainted with the sizes and growth of the O-group larvæ. In June r920 the four or five thousand specimens taken varied from 7 to $37 \mathrm{~mm}$. in length, with an average of $25 \mathrm{~mm}$.

In the course of the autumn and winter, the great bulk of the first-year larvæ (the O-group) disappears from the spawning grounds in the western Atlantic, but 
a number of stragglers remain there throughout the winter, appearing in the following spring as a I-group, sharply distinguished in point of size from the young fry of the O-group which have come into being mean-

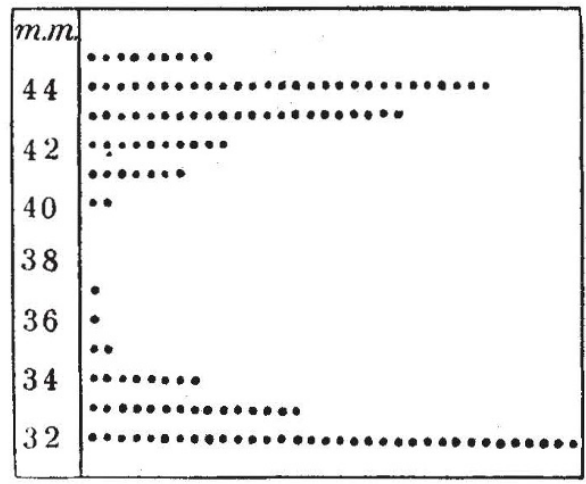

FIG. 4.-European eel (Angwilla vulgaris); western Atlantic (west of $50^{\circ}$ long. W.), Dana, June 1920 Showing limit between O-group and I-group.

time (see Figs. 3 and 4). These specimens of the I-group, however, found in early summer west of $50^{\circ} \mathrm{W}$. long., are comparatively few. The great majority, now measuring 50-60 mm., have, in the course of the winter, moved north-east and east, and are now in the central Atlantic, about as far as the longitude of the Azores, or even some distance farther east. In the following year again, by early summer, these larvæ have attained their full size, averaging about $75 \mathrm{~mm}$., and appear now, as a II-group, off the western shores of Europe and far up in the Mediterranean, having, in the latter case, passed in through the Straits of Gibraltar during the winter, or in the autumn.

The retrograde metamorphosis of the full-grown larvæ takes place in the course of the autumn and winter. In the process, they become elvers, and in spring, being then three years old (the III-group) move up into fresh water, when the temperature of the latter permits. At this stage of development they resemble miniature eels (Fig. 5). The average length is about $65 \mathrm{~mm}$., but they have lost greatly in dimensionsand weight during metamorphosis, running no fewer than ${ }_{5} 00$ specimens to the pound. In England, it is more especially on the west coast, in the Bristol Channel, that the elvers ascend in very great quantities during the spring, the phenomenon being generally known among the inhabitants, who catch them for human consumption, or even for feeding pigs. The name "elver," too, comes from this part of the country. There are interesting accounts from Gloucester telling how, in March and April, fishermen stand in hundreds along the river banks, each with a hand net, fishing for elvers, and often making astonishingly large catches - a hundredweight of fish per man in one night. Bearing in mind the fact that I 500 elvers go to the pound weight, it will be realised that enormous quantities of eel fry must come in every year to the coasts of Europe from the Atlantic, numbers answering well to the great masses of tiny larvæ we found with the Dana on the breeding grounds of the eel in the western Atlantic. In 1920, I921 and 1922, we found first-year larvæ (O-group) of the respective years on those grounds, but at this present time of writing (October r922), none of these will yet have reached their destination, the fresh waters of Europe. Not until next spring (1923) will the fishermen of the Bristol Channel be able to catch elvers of the r920 stock, which appeared in our nets in the western Atlantic in June r920, and are shown in Fig. 2. And not until $2 \frac{1}{2}$ years from now-that is to say, in the spring of 1925 -will the r922-year class, specimens of which were taken by the Dana expedition about six months ago (April and May 1922) near Bermuda, make their entry into the Severn.

Moving eastward, then, across the Atlantic, the eel fry come to the shores of Europe, and it is natural that here they should be found in greatest numbers. It is here also, that the capture of them has developed into an actual industry, as for example, apart from the Bristol Channel, also at several places in the south-west of Ireland, but especially on the west coast of France and the northern shores of Spain. ${ }^{2}$ They are taken here

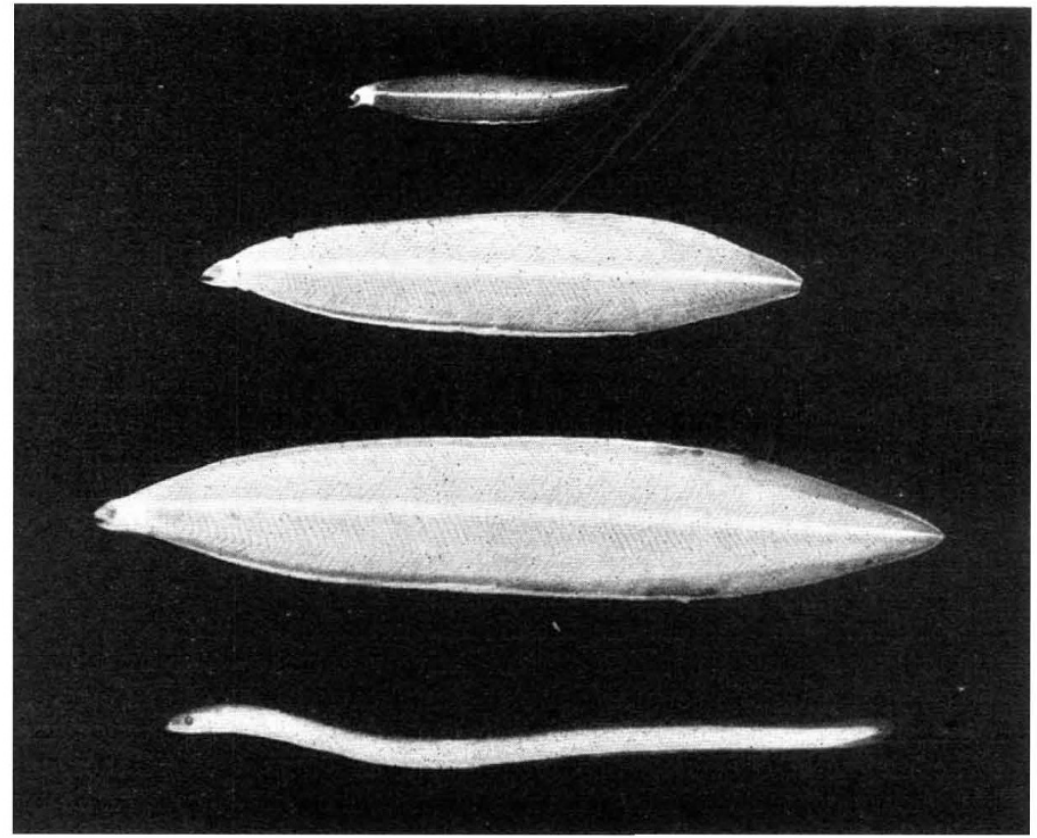

FIG. 5.--European eel (Anguilla vulgaris); showing the size of the four youngest year-classes (O-, I-, II-, and III-groups) in June ; slightly enlarged: the top specimen measures $25 \mathrm{~mm}$. in

in tons, and the inhabitants have special names for them (civelles or pibales in France, and angúlas in Spain).

It must not be imagined, however, that all the eel fry coming from the Atlantic will be stopped by the west coasts of Europe. Great numbers of them continue

${ }^{2}$ Also at some places in the western Mediterranean on the west coast of Italy, the elver fishery reaches the status of an industry in itself. 
on their way-living semi-pelagically-to the eastward, until the metamorphosis is completed, and the small eel young have acquired a dark covering of pigment. In Northern Europe they move-by way of the Channel and round the north of Scotland-through into the North Sea and farther, via the Danish waters, to the western parts of the Baltic, where they have been found so far east as E. of Bornholm, at stages where the metamorphosis was not yet quite completed (Dr. A. C. Johansen, with the Thor), Fig. x. In the northern parts of the Baltic, elvers are not known, or indeed any eels less than $20-30 \mathrm{~cm}$., though the eel occurs right in to the innermost waters of that sea. The eels found in Finland are large females, and on the east coast of Sweden no males have been found north of lat. $57^{\circ} \circ 8^{\prime}$ (off Öland) ; see Fig. I. This peculiar fact evidently answers to what we know from the great rivers, where the female eels generally move farther up into the higher reaches than the males.

The eel fry enter the Mediterranean at an early stage, as unmetamorphosed larvæ, most often not even having attained their full larval size, between one and a half and two years old. As unmetamorphosed larvæ they are found throughout the western basin, west of Italy, and at times, perhaps, still farther to the eastward. Even in the most easterly parts of the Mediterranean, an ascent of elvers takes place, these being transparent, and thus not having fully completed their metamorphosis. I have in this connexion received some information, with samples, from Mr. Geoffrey W. Paget, Director of Fisheries Investigations in Cairo. At a pumping station near Alexandria, where fresh water is pumped in large quantities into a channel leading direct to the sea, Mr. Paget found, on February 24, 1920, "that elvers were present in prodigious quantities, being unable to proceed further on account of the station. From this date-February 24-until April I $_{5}$, fishing was practically continuous, and we transported over $5,000,000$ elvers to the canal systems inland." Mr. Paget's observations are highly interesting, showing as they do that elvers which have not yet completed their metamorphosis can occur in such great quantities so far east as about $30^{\circ} \mathrm{E}$. long. Together with observations from northern Europe, they give us a clear picture of the remarkable power of migration possessed by the eel fry. From the breeding grounds in the western Atlantic to the mouth of the Nile is a distance approaching 90 degrees of longitude, or one-fourth of the earth's circumference, and this distance is covered by the eel fry in the space of about three years. They may reach the Nile and the western Baltic before their metamorphosis is yet complete, and the greater part of the journey is made while they are still in the leaf-shaped larval stage. No other instance is known among fishes of a species requiring a quarter of the circumference of the globe to complete its life history, and larval migrations of such extent and duration as those of the eel are altogether unique in the animal kingdom.

\title{
Theories of Magnetism.
}

\author{
By Dr. A. E. Oxley.
}

$\mathrm{M}$ $\mathrm{UCH}$ attention has been devoted in recent years to theories of magnetism, and an interesting survey of the position of the subject is given in the report of a committee of the U.S. National Research Council issued by the National Academy of Sciences, Washington, in August last (vol. 3, part 3). It is difficult in a descriptive article of moderate length to present judicially the various views which have been advanced, but an attempt will here be made to do this, using the report referred to as a basis, and supplementing it with accounts of one or two advances not recorded therein.

Poisson in 1820 published a mathematical theory of magnetism which was based on Coulomb's inverse square law. He merely regarded magnetic substances as possessing positive and negative magnetic fluids which could be separated by the application of an external magnetic field resulting in the production of the magnetic effects as observed in bar magnets. This theory was eventually (I83I) shown to be untenable by Faraday's discovery of the phenomenon of diamagnetism.

Ampère's theory (I825), based on Oersted's discovery (I820) of the magnetic effects of an electric current, may be regarded as the foundation of modern magnetic theories, though at that time the laws of electromagnetic induction were unknown. This theory led Weber (1854) to develop a theory which aimed at an explanation of the magnetic effects of bar magnets on the assumption that the molecules were always equivalent to miniature magnets, whether the substance were magnetised or not, the action of the external field being merely to align the miniature magnets along the direction of the applied field. No explanation of the phenomenon of hysteresis was given, however, until Maxwell ("Electricity and Magnetism," $\S 444)$ extended Weber's views and interpreted the more complicated hysteresis effects in terms of certain quasi-elastic forces.

The theory of Ewing ( 1890 ) enabled us to visualise the nature of these hypothetical controlling forces by attributing the sluggishness of the response to an applied field as due to the interaction between special groups of molecules. This gave a rough explanation of hysteresis effects in terms of the mutual actions between complex groups of molecular magnets, and accounted for the shape of the hysteresis loops, the coercive force and the retentivity of a ferro-magnetic substance like iron.

At the beginning of the present century, attempts were made by Voigt and J. J. Thomson to outline an electron theory of magnetism based on the magnetic effects of a moving electron, but it was not until the theory of paramagnetism and diamagnetism of Langevin appeared (1905) that a satisfactory interpretation of these phenomena was presented.

The classical researches of Curie (1895) had shown that substances could be divided into three groups as regards their magnetic properties under an external field. These are, (I) diamagnetic substances, which show a minute negative induced moment, practically independent of temperature; (2) paramagnetic sub- 